\title{
Simulation of signal received by a Dual-wavelength Micro-pluse lidar
}

\author{
Feng Jiang ${ }^{\mathrm{a}}$, Yunqing Liu, ${ }^{\mathrm{b}}$, \\ College of Electronic and Information Engineering, Changchun University of Science and \\ Technology, Changchun, Jilin, 130011, China \\ a3106300@qq.com,b234577142@qq.com
}

Keywords: dual-wavelength MPL, simulation model, atmospheric detect.

\begin{abstract}
In this paper, according to the principle of micro pulsed laser radar detection, the appropriate atmospheric model is used to simulate the double pulse laser radar. And the simulation results are verified by experiments.
\end{abstract}

\section{Introduction}

Atmospheric aerosol and cloud are two important factors that affects the climate change and the atmospheric environment. Micro pulse laser radar, which is referred to as MPL,is a new type of laser radar system developed in recent years. The key parts of MPL are whole solidification structure or modular structure which are light and small, coupled with the unique design of transmitting and receiving optical system, so it has the advantages such as simple structure, small volume, light weight, low cost, high degree of automation and so on. For it can run continuously day and night, the MPL has become one of the most effective way to detect atmospheric aerosol and cloud.

In order to understand how the MPL system parameters affect the of the detection, but also provide theoretical analysis basis for instrument development work, according to the micro pulse lidar equation, using the appropriate atmospheric model, we simulated the backward scattering field of the atmosphere of MPL accept echo signal and detecting the echo signal SNR.

\section{Atmospheric Model}

Atmospheric model is straight for the intensity of echo signal received by MPL in the simulation, in order to get practical reasonable simulation result, a certain atmospheric model must be set.

The atmospheric parameters which the simulation system needed mainly includes: the backward scattering field of different level of atmospheric aerosol and extinction coefficient, the backward scattering field of air molecules with the extinction coefficient, atmospheric temperature and pressure under standard atmosphere model.

The atmospheric model for the system is the standard atmosphere model USSA76, which is issued in 1976 by the United States. The model is commonly used as space atmospheric model. The applicable scope of the model is $0-1000 \mathrm{~km}$, and it is divided into underlying $(0-86 \mathrm{~km})$ and senior (86-1000 - km) two parts. Since May 1, 1980, China's state administration of standard American standard atmosphere model USSA76 $30 \mathrm{~km}$ below the part of the chosen for China's standard atmosphere model (GB1920-80). China's state administration of standard choose the part below $30 \mathrm{KM}$ of the Amermuican standard atmosphere of USSA76 model as China's standard atmosphere model (GB1920-80) since May 1980.

Benchmark atmosphere parameter values of the model is as follow:

The temperature: $\mathrm{T} 0=288.15 \mathrm{~K}$;

The pressure: $\mathrm{P} 0=101325 \mathrm{~Pa}$;

The density: $\rho_{0}=1.225 \mathrm{~kg} / \mathrm{m} 3$;

The air temperature, air density and atmospheric pressure at the height below $11 \mathrm{~km}$, can be calculated by using the following formula:

$$
\begin{aligned}
& \mathrm{T}=\mathrm{T}_{0}\left(1-\frac{\mathrm{h}}{44329}\right) \\
& \rho=\rho_{0}\left(1-\frac{\mathrm{h}}{44329}\right)^{4.255876}
\end{aligned}
$$




$$
\mathrm{P}=\mathrm{P}_{0}\left(1-\frac{\mathrm{h}}{44329}\right)^{5.255876}
$$

The air tempeature, air density and atmospheric pressure at the height between $11 \mathrm{~km}-20 \mathrm{~km}$, can be calculated by using the following formula:

$$
\begin{aligned}
& \mathrm{T}=0.751865 \mathrm{~T}_{0} \\
& \rho=0.297076 \rho_{0} \mathrm{e}^{\left(\frac{10999-\mathrm{h}}{6341.4}\right)} \\
& \mathrm{P}=0.223361 \mathrm{P}_{0} \mathrm{e}^{\left(\frac{10999-\mathrm{h}}{6341.4}\right)}
\end{aligned}
$$

\section{Dual-wavelength Micro-pluse lidar}

Dual-wavelength Micro-pluse lidar consists of transmitting, receiving, control and data acquisition subsystem. ND: YAG laser is choose as Launch subsystem, which can lunch laser signal with wavelength of $1064 \mathrm{~nm}$ and $532 \mathrm{~nm}$, pulse energy of 280 and $260 \mathrm{~mJ}$ respectively. Cassegrain telescope is choose as receiver.The system uses four channels to receive the atmospheric echo signal of the lower and middle upper part 532 and $1064 \mathrm{~nm}$ of the troposphere, respectively. Effectively shortening the time to obtain atmospheric information.

\section{Principle of MPL Atmospheric Detection}

MPL detection equation can be expressed in the laser radar detection equation, which is described as:

$\mathrm{E}(\lambda, \mathrm{Z})=\frac{\mathrm{E}_{\mathrm{L}} \mathrm{k}(\lambda) \mathrm{A}_{0}\left(\frac{\Delta \mathrm{Z}}{\mathrm{Z}^{2}}\right) \beta(\lambda, \mathrm{Z}) \mathrm{T}^{2}(\lambda, \mathrm{Z})+\mathrm{E}_{\mathrm{b}}+\mathrm{E}_{\mathrm{ap}}}{\mathrm{C}_{\mathrm{d}}}$

where $E_{L}=$ the emission energy of laser ;

$\mathrm{Z}=$ detection range;

$\mathrm{A}_{0}=$ The receiving area of the telescope;

$\Delta \mathrm{Z}=$ detection range resolution of the system;

$\mathrm{E}_{\mathrm{b}}=$ Energy of atmospheric background noise;

$\mathrm{E}_{\mathrm{ap}}=$ the noise caused by the rest of probe pulse ;

$\mathrm{C}_{\mathrm{d}}=$ calibration detector response factor.

$\mathrm{T}^{2}(\mathrm{z})=$ Double atmospheric transmittance which is the degree of attenuation after that laser come from the transmitter to the receiver gone through the atmosphere between MPL and target twice. It is described as:

$$
\mathrm{T}^{2}(\mathrm{z})=\exp \left\{-2 \int_{0}^{\mathrm{h}} \alpha(\mathrm{z}) \mathrm{dh}\right\}
$$

The relationship between the atmospheric backscatter echo power at the height $\mathrm{Z}(\mathrm{E}(\lambda, \mathrm{Z}))$ and the atmospheric backscatter echo photon number Ns (Z) received by M P L can be expressed as

$\mathrm{N}_{S}(\mathrm{Z})=\left(\frac{\eta \lambda}{\mathrm{hc}}\right) \mathrm{E}(\lambda, \mathrm{Z}) \Delta \mathrm{t}$

where $\eta=$ the quantum efficiency of the detector

$\lambda=$ The wavelength of the emitted laser(nm)

$\mathrm{h}=6.626276 \times 10-34 \mathrm{~J} \cdot \mathrm{s}$, which is Planck constant

$\mathrm{c}=3 \times 108 \mathrm{~m} / \mathrm{s}$, which is speed of light

$\Delta \mathrm{t}=$ acquisition time of MPL photon counter

The sky background light $\mathrm{Nb}$, as well as the dark count $\mathrm{Nd}$ generated by the detector are received by MPL when it receives the atmospheric backscattered light. They can be expressed as:

$\left\{\begin{array}{c}\mathrm{N}_{\mathrm{b}}=\left(\frac{\eta \lambda}{\mathrm{hc}}\right) \mathrm{P}_{\mathrm{b}} \pi\left(\frac{\theta}{2}\right)^{2} \Delta \lambda \mathrm{A}_{0} \mathrm{~T}_{0} \Delta \mathrm{t} \\ \mathrm{N}_{\mathrm{d}}=\mathrm{CPS} \cdot \Delta \mathrm{t}\end{array}\right.$

where $\mathrm{P}_{\mathrm{b}}$ is sky background radiation brightness which is set to $0.2 \mathrm{~W} / \mathrm{m} 2 \cdot \mathrm{sr} \cdot \mathrm{nm}$ in the daytime as well as 0 in the night time.

$\theta$ is the reception field of view of the receiving telescope (ard);

$\Delta \lambda$ is the half width of the filter(nm); 
$\mathrm{A}_{0}$ is the effective receiving area of the receiving telescope $(\mathrm{m} 2)$; $\mathrm{T}_{0}$ is the transmittance of the receiving optical system;

CPS is the dark count of the detector(s-1);

\section{Simulation Results and Analysis}

The analog signal of the double wavelength MPL(fig.1) is compared with the atmospheric backscatter signal received by the real radar system(fig.2). It can be seen from the figure, in the entire detection range, the analog detection signal and the actual detection signal is basically the same. The consistency of the two shows that the model used in the simulation is appropriate and the calculation method is correct. This model can be used as the theoretical basis for the selection of system parameters when the dual wavelength micro pulsed laser radar is developed.

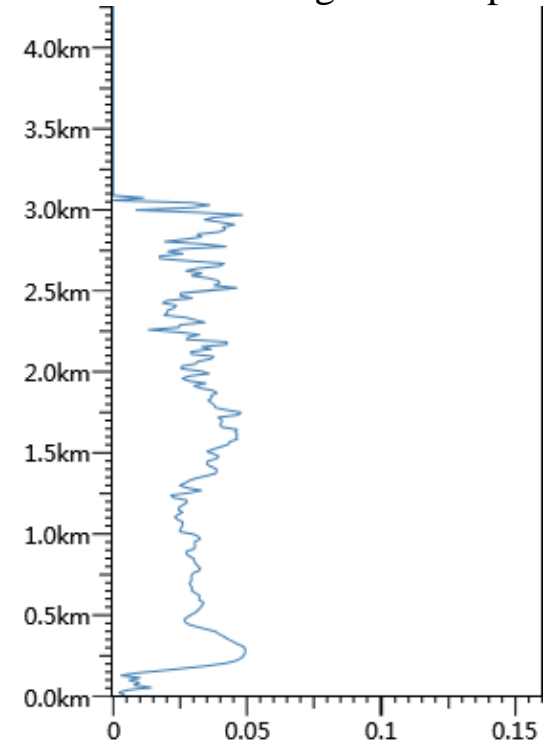

Fig. 1 analog signal of the MPL

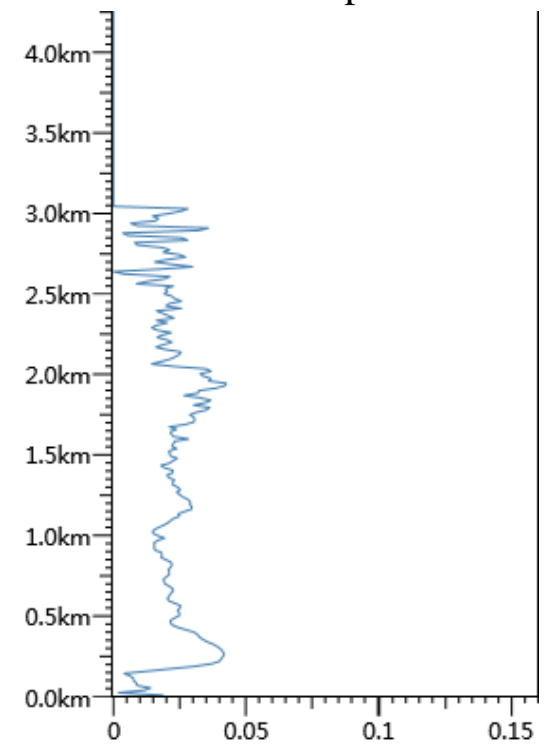

Fig. 2 the atmospheric backscatter signal received by the real radar system

\section{References}

[1]. Du qicheng, Ji Yufeng, Xu Chidong. Data processing method of aerosol horizontal distribution detected by MPL[J]. Journal of Atmospheric and Environmental Optics,2008,3(1):23-27(in Chinese)

[2]. Strawbridge K B,Snyder BJ. Daytime and night-time aircraft lidar measurements showing evidence of particulate matter transport into the Northeastern valleys of the Lower Ftaser Valley,BC[J].Atmospheric Environment,20004,38(34):5873-5886

[3]. Zhou Xiuji,Tao Shanchang, Yao Keya. Advanced Atmospheric Physics[M].Beijing:China Meteorological Press, 1991,1200-1242(in Chinese)

[4]. Spinhirne J D.Micro pluse lidar [J].IEEE Trans. Geosc. Remote Sensing, 1993,31:48-54 